\title{
Urodimento
}

REVISTA DE ESTUDOS EM ARTES CÊNICAS

E-ISSN 2358.6958

\section{Performatividade e simulacro: A performance cênica como acontecimento e sua reprodução}

\author{
Marcelo Puppi Munhoz
}

Para citar este artigo:

MUNHOZ, Marcelo Puppi. Performatividade e simulacro: A performance cênica como acontecimento e sua reprodução. Urdimento - Revista de Estudos em Artes Cênicas, Florianópolis, v. 2, n. 41, set. 2021.

do) DOI: http:/dx.doi.org/10.5965/1414573102412021e0207

Este artigo passou pelo Plagiarism Detection Software | iThenticate 
Performatividade e simulacro:

A performance cênica como acontecimento e sua reprodução

\title{
Resumo
}

Marcelo Puppi Munhoz 1

Este artigo examina a performatividade da reprodução da performance cênica através de uma revisão bibliográfica que passa, inicialmente, pelo estabelecimento de um paralelo entre a noção austiana de performativo e o conceito deleuziano de acontecimento. A análise segue através de ajustes propostos por Fischer-Lichte, Goffman, Butler e Colling para localizar de forma mais distinta a potência performativa na performance cênica presencial. Finalmente, procura-se destacar uma potência correspondente no contexto da reprodução das performances cênicas recorrendo à positividade do conceito de simulacro proposta por Deleuze e comentadores.

Palavras-chave: Performatividade da reprodução. Performance. Simulacro.

\section{Performativity and simulacrum: Performance as an event and its reproduction}

\begin{abstract}
This article examines the performativity of the reproduction of performance through a bibliographic review that initially passes through the establishment of a parallel between the Austian notion of performative and the Deleuzian concept of event. The analysis follows through adjustments proposed by Fischer-Lichte, Goffman, Butler and Colling to locate the performative power in the presential performance in a more distinct way. Finally, we seek to highlight a corresponding power in the context of the reproduction of performances using the positivity of the concept of simulacrum proposed by Deleuze and commentators.
\end{abstract}

Keywords: Reproduction performativity. Performance. Simulacrum.

\section{Performatividad y simulacro: La performance como acontecimiento y su reproducción}

\section{Resumen}

Este artículo examina la performatividad de la reproducción de la performance escénica a través de una revisión bibliográfica que pasa inicialmente por el establecimiento de un paralelismo entre la noción austiana de performativo y el concepto deleuziano de acontecimiento. El análisis sigue a través de los ajustes propuestos por Fischer-Lichte, Goffman, Butler y Colling para ubicar el poder performativo en la performance escénica presencial de una manera más distinta. Finalmente, busca resaltar un poder correspondiente en el contexto de la reproducción de las performances utilizando la positividad del concepto de simulacro propuesta por Deleuze y comentaristas.

Palabras clave: Performatividad de la reproducción. Performance. Simulacro.

${ }^{1}$ Mestre em Filosofia pela Pontifícia Universidade Católica do Paraná (PUCPR). Bacharel em Jornalismo pela Universidade Federal do \{Paraná (UFPR). Professor do Curso de Teatro em PUCPR. marcelomunhoz71@gmail.com 
A filosofia de Gilles Deleuze, que tem a diferença como princípio unívoco, também pode receber o nome de filosofia do acontecimento (Zourabichvili, 2016), já que, para o filósofo francês, falar em acontecimento significa dizer que algo muda: sim, em uma instância corporal, mas, sempre, necessariamente, em uma instância incorporal. Ou, ainda, o sentido de algo muda: seja por causa de um terremoto, de uma batalha, de uma peste, de uma descoberta científica, da formulação de um conceito, das imagens de um crime ou da mais singela experiência, artística ou não, que abala nosso campo simbólico em foro íntimo ou coletivo. Um novo dado se apresenta de forma suficientemente relevante para alterar, sutil ou drasticamente, nossa imagem da realidade. Isso é o que Deleuze define como um acontecimento, a partir do qual se estrutura uma lógica aberta, capaz de redefinir as representações do mundo porque acolhe na linguagem não somente o estado das coisas, mas o devir delas: não somente substantivos, mas verbos, não somente qualidades, mas atributos, efeitos incorporais ${ }^{2}$, no que vem a se tornar o complexo acontecimento-sentido.

Encontramos uma correspondência do acontecimento deleuziano com a noção austiana de performativo na forma como foi amplamente apropriada pelos estudos das artes ${ }^{3}$. A perspectiva de John L. Austin, segundo Danilo Marcondes de Souza Filho (in Austin, 1990), adere à chamada filosofia da linguagem ordinária, que não encontra uma distinção radical entre "linguagem" e "mundo" por considerar que a "realidade" é sumamente formada pela linguagem na forma como a adquirimos e utilizamos. Daí, o paradigma que considera a linguagem como ação, "como forma de atuação sobre o real, e portanto de constituição do real, e não meramente de representação ou correspondência com a realidade" (Austin, 1990, p.10 - grifo do autor). Vamos relembrar: Austin distingue uma sentença, que é mera afirmação ou negação, passível de ser falsa ou verdadeira, de uma enunciação,

\footnotetext{
2 Uma imagem famosa, inicialmente formulada pelo filósofo francês Emile Bréhier (1876-1952), quando este reconstituiu o pensamento estoico, é usada por Deleuze para explicar o acontecimento: "Quando o bisturi corta a carne, o primeiro corpo produz sobre o segundo não uma propriedade nova, mas um atributo novo, o de ser cortado. O atributo não designa nenhuma qualidade real..., é sempre ao contrário expresso por um verbo, o que quer dizer que é não um ser, mas uma maneira de ser..." (Bréhier, 1928, p.11-13 apud Deleuze, 2015, p.6).

Ainda que tenha sido exaustivamente analisado e discutido, permitimo-nos aqui resgatar alguns pontos do itinerário da construção do conceito de performativo pelo linguista britânico John L. Austin (1990) na série de conferências How to do things with words, proferida por ele em Harvard (1955), já que retornaremos a eles com frequência ao longo desse trabalho.
} 
que situa o falante em momento, local e condições determinadas. Em ambos os casos, a verdade está submetida à adequação entre a linguagem e a realidade, mas, nas enunciações, ela é acrescida pelo conceito de eficácia como ato, do quão "felizes" são esses atos, dependendo das suas condições institucionais.

Austin faz ainda outra distinção: anunciações constatativas são descrições de ações ou estados de coisas ("Eles se casam"); enunciações performativas são realizações de ações ("Eu os declaro marido e mulher", "Eu batizo este navio..." ou ainda "Eu juro"). O termo é derivado do inglês to perform, ligado à ideia de agir, realizar. São atos de fala. Aqui se localiza, em nossa visão, a conexão com o conceito deleuziano de acontecimento. Um pacto conjugal bem sucedido não produz uma nova qualidade (física) nos entes envolvidos, mas gera um novo atributo (estar casado), assim como o bisturi não altera a qualidade da carne, mas produz nela um novo atributo, o de ser cortado. O sucesso desse ato, no entanto, depende de condições não-linguísticas institucionais e sociais. Acontece que, ao avançar no esforço para distiguir anunciações constatativas e performativas, Austin encontra mais e mais exemplos nos quais as primeiras funcionam como atos ou realizações. Por exemplo, as enunciações constatativas "Eu ficarei aqui" ou "Eles o esperam" podem ser atos de ameaça ou desafio. Em todos esses casos, no entanto, a linguagem como fala constitui ação, e esta, por sua vez, reposiciona isso que chamamos de "realidade" através da linguagem4.

\section{Performance cênica e performatividade}

Passamos à pergunta seguinte: é possível considerar uma performance cênica ${ }^{5}$ como uma enunciação performativa? Respeitando os fundamentos

\footnotetext{
${ }^{4}$ As implicações dos atos de fala, ou seja, de como a dimensão da linguagem age sobre a dos corpos, e viceversa, é aprofundada por Deleuze e Guattari (1995) ao tratar dos regimes de signos, chegando à síntese da noção de máquina abstrata: o agenciamento físico e semiótico que opera de forma diagramática sobre a matéria. Mas, por hora, o exame do ato de fala performativo em Austin nos parece suficiente para perceber como esse conceito foi apropriado e adaptado pela estética do performativo para chegar ao estatuto de uma "estética do acontecimento".

5 Usaremos "performance cênica" na busca por um conceito abrangente, como o empregado por Erika Fischer-Lichte em sua Estética do Performativo (Ästhetik des Performativen, 2004) para se referir ao acontecimento cênico. No original alemão, o termo empregado é "Aufführung", comumente traduzido para o português como atuação, apresentação ou récita - palavras, a nosso ver, insuficientes para alcançar a amplitude do conceito como é desenvolvido pela pesquisadora alemã. A edição espanhola da obra (2011) opta pelo termo "realización escénica", que aponta para a "realidade" em si do evento cênico. No entanto, à
} 
centrais do conceito cunhado por Austin, é possível dizer: que um performer (1) empenha sua palavra (2) em um contexto institucional (3) que propicia a produção de uma nova realidade? Para a pesquisadora alemã Erika Fischer-Lichte, a noção de performativo, nesse caso, exige algumas revisões.

A primeira delas vem da filosofia da linguagem. Desde a virada linguística dos anos 70 até fins dos anos 80, havia a compreensão de "cultura como texto": os fenômenos sociais seriam observados e "lidos" como signos presentes na cultura passíveis de serem interpretados. Segundo Fischer-Lichte, essa abordagem mudou substancialmente a partir dos anos 90:

[...] viemos a perceber que a cultura é também, se é que não é primeiro que tudo, performance. Não é possível ignorar até que ponto a cultura é produzida como e em performance - não só nas "representações" proporcionadas pelas diferentes artes, mas também e antes de tudo nas "representações" associadas a rituais, festivais, comícios políticos, competições desportivas, mostras de moda e coisas do gênero (FischerLichte, 2005, p.73 - grifos da autora).

A cultura de uma época se enuncia de forma evidente em suas diversas performances, não só naquilo que ali se expressa mas naquilo que se ritualiza, que se performa, que se converte em ação. Para Deleuze, todo enunciado é uma emissão de singularidades de um dado momento histórico: "Não há possível nem virtual no domínio dos enunciados; nele tudo é real, e nele toda realidade está manifesta: importa apenas o que foi formulado, ali, em dado momento, e com tais lacunas, tais brancos" (Deleuze,1988, p.15). Tudo que devém em cena - palavras, gestos, objetos, espaço, participantes, contexto - e, mais que tudo, as lacunas, os vazios presentes no campo, renovam a produção de sentidos que emergem nessa relação - compondo não só uma, mas inúmeras enunciações.

Mas, a questão continua sendo o quanto esses dados novos alteram os estados de coisas até então vigente. Voltando aos preceitos de Austin, para

luz de nossa análise na perspectiva deleuziana, não faz sentido falarmos em "realização", em vista da realidade já virtual da performance que, em seu ato, meramente se atualiza no aqui e agora. Para Renato Cohen (2002, p. 27 - grifo nosso), performance é "antes de tudo uma expressão cênica: um quadro sendo exibido para uma plateia não caracteriza uma performance; alguém pintando esse quadro, ao vivo, já poderia caracterizá-la". Essa definição convida para uma visão abrangente do termo, envolvendo indistintamente artes visuais, música, teatro e arte da performance, que nos parece condizente com a forma como o termo "Aufführung" é empregado por Fischer-Lichte. Assim, optamos pelo termo "performance cênica". 
alcançar sua dimensão performativa, o ato exige um respaldo social e institucional. E, aqui, cabe destacar que, na perspectiva do ato performativo visto como acontecimento, não só a "instituição arte” merece ser colocada em questão, mas também a noção de "realidade". Uma contribuição valiosa para essa perspectiva nos parece vir de Erving Goffman em seu livro Frame Analysis - An Essay on the Organization of Experience (1986), onde ele desenvolve a noção de marco institucional, para mostrar como a experiência cotidiana é organizada institucionalmente com base em enquadramentos (frames): construções da realidade que se articulam entre si e adquirem sentido ao se relacionarem umas com as outras. Ele parte do pressuposto de que tomar a palavra é sempre fazêla diante de um público, para e com este público, ou seja, trata-se sempre de uma performance. A "pureza" da performance varia "de acordo com a exclusividade da reivindicação dos observadores sobre a atividade que eles assistem" (Goffman, 1986, p.124). De fato, no teatro, em shows de comédia, dança e outras manifestações, inclusive assembleias políticas, se não há audiência, não há performance. E nesses atos de fala e escuta conjuntas, estabelecem-se convenções que possibilitam a comunicação entre os participantes constituindo uma certa perspectiva de mundo, enquadramento (frame) ou marco.

Para Goffman, todas as atividades sociais podem ser observadas a partir dos enquadramentos presentes, tomados como referências ou mesmo modelos uns em relação aos outros. Um marco se forma com os participantes referindo-se a outros marcos, que aderem ou remetem a marcos das experiências individuais e assim se articulam em um marco comum, provisório, útil para a comunicação e organização da experiência coletiva em cada ocasião. A forma como as pessoas se reúnem, as motivações que as conduzem até lá, as expectativas, os atos que ali se realizam: os enquadramentos possibilitam que os "atores" de uma "cena social" produzam uma imagem conjunta de realidade. Fora desse quadro ou marco, essa visão de realidade pode ser fragilizada. Boa parte da relevância de uma performance pode estar, por exemplo, em como atos performativos instauram coletivamente a problematização dos limites dos marcos institucionais presentes, em como eles abalam, portanto, imagens anteriores da realidade e reposicionam essas imagens. O paralelo com o conceito deleuziano de 
acontecimento é evidente, mas, vale destacar: ainda que falemos em "participantes" desses eventos, estamos, de fato, nos referindo a conjuntos de singularidades, de pontos singulares que assinalam pessoas psicológicas e morais, identidades.

Dando um passo adiante nesse sentido, poderíamos dizer que os elementos presentes nos enquadramentos, na medida em que formam imagens da realidade, são capazes de reposicionar também as identidades (autoimagens) dos participantes? Judith Butler (2018) mobiliza o conceito de ato performativo para desenvolver sua teoria de que a identidade de gênero não é uma forma de identidade pré-determinada biológica ou ontologicamente, mas o resultado de atos constitutivos realizados pelos indivíduos ao longo do tempo no âmbito da cultura. Se a identidade de gênero é constituída no tempo através da reiteração de um estilo de ações historicamente associadas a este ou àquele gênero, então a transformação de um gênero é passível de acontecer pela alteração dos parâmetros deste ou daquele estilo de ações. Ela cita Merleau-Ponty (1999, p. 236) quando ele diz que o homem é uma “ideia histórica” e não uma espécie natural: "Tudo aquilo que somos, nós o somos sobre a base de uma situação de fato que fazemos nossa, e que transformamos sem cessar por uma espécie de regulagem que nunca é uma liberdade incondicionada." Não se trata de negar aspectos naturais do corpo, mas de reconhecer que processos de significação cultural operam de forma distinta: uma coisa é a condição natural da "fêmea", outra é a construção cultural da "mulher" formada por uma herança histórica passível de transformação e "regulagem" constante.

Corpo, neste caso, é entendido como "um processo ativo de corporificação de certas possibilidades culturais e históricas” (Butler, 2018, p.4). Um gênero não é posse de algo, mas atuação sobre algo que já está em curso, como um ator que entra em cena, e neste caso o gênero é um conjunto de ações que vem sendo ensaiadas pelo ator que está agora em cena, mas também por atores antes dele, cada um com seus corpos e histórias, que constituíram formas mais ou menos delineadas de caracterização. Dado gênero somente tem atualidade ou existência com ações e corpos de atores sociais que, através da repetição da performance e de sua substancial diferença, produzem novas realidades do gênero e apontam 
para processos identitários passíveis de extensão para outras categorias de identidade.

Aqui cabe apontar uma ressalva que a própria Butler faz quando diz que uma travesti performando gênero no palco ou sentada ao nosso lado no ônibus são duas coisas muito distintas: "No teatro é possível dizer 'isso é só atuação', e assim desrealizar o ato, ou seja, separar completamente a atuação da realidade” (Butler, 2018, p.12). A potência performativa (de produção de realidade) de uma performance irá sempre depender do teor e forma da enunciação, bem como de seu contexto cultural e institucional, mas estas variáveis desestabilizam essa mesma distinção entre atuação e realidade apresentada por Butler de forma tão dicotômica. Leandro Colling (2021) faz uma extensa análise de estudos e trabalhos de artistas da performance para problematizar dicotomias entre performance de gênero e performatividade de gênero: "as obras e as vidas dos/as artistas são indissociáveis e, muitas vezes, a própria identidade de gênero e sexual é o motor das performances" (Colling, 2021, p.16-17). De fato, produz-se aí um campo bastante dinâmico de experimentação, de exploração identitária.

Essas perspectivas nos ajudam a perceber como a "realidade" é uma construção, e performar é sempre atuar sobre algo em andamento, em uma instância corporal e incorporal, passível de ter seus sentidos revistos ou reinventados. Ao reconhecermos o potencial da performance (1) como enunciação, (2) como constituição de imagens coletivas da realidade e (3) como construção de identidades pessoais, conseguimos de forma mais clara conceber uma dimensão performativa (acontecimental) da performance cênica em si.

\section{Reprodução da performance e performatividade}

Quando falamos de performance cênica, nos referimos a algo efêmero que começa com o encontro entre atores e espectadores, se constitui enquanto dura e dura somente enquanto produz a si mesma, como um sistema ou organismo vivo. Para Erika Fischer-Lichte (2011), esta noção coincide com a de autopoiese, termo criado pelos biólogos chilenos Humberto Maturana e Francisco Varela, para identificar o aparecimento e o desaparecimento da vida. A noção de autopoiese se 
desenvolve a partir da pergunta: "Quais são os critérios que definem quando um ser está ou não vivo?”. Maturana e Varela (2003) lembram que, ao longo da história da ciência, vários parâmetros foram propostos (composição química, movimento, reprodução...), sempre criando muitas dificuldades. Sem ignorar essas condições, eles sugerem, por outro lado, partir da constatação de que toda forma de vida supõe uma organização, ou seja, um conjunto de relações precisa existir entre as partes de algo para que ele seja o que é. Eles exemplificam essa ideia apontando para uma cadeira: há ali uma relação entre suas partes - pernas, encosto e assento - que torna possível que eu me sente ali, independentemente dos materiais de que essas partes são feitas. Para Maturana e Varela (2003), a característica central dos seres vivos é que eles se produzem continuamente. Esta produção se dá em uma rede chamada de metabolismo celular, que, ao mesmo tempo em que opera uma troca entre seus componentes, também constitui um limite para a rede, uma membrana que, ainda que seja permeável, define claramente um dentro e um fora. A rede de transformações que se estabelece entre seus componentes é condição para a membrana e a membrana é a condição para que seus componentes operem como uma rede. Isso é o que define um sistema autopoiético: que ele, pela dinâmica que produz entre seus componentes se distinga de seu entorno, definindo uma borda que o mantém operante como sistema.

Como os seres vivos e organismos, a performance cênica se constitui e se regula em sua multiplicidade por um sistema batizado por Fischer-Lichte de espiral de retroalimentação autopoiética ${ }^{6}$ : atores e espectadores nutrindo-se mutuamente em uma rede produtiva de ações, percepções, afecções e, também, processos de significação e identificação. Aqui está pressuposto, de um lado, o engajamento ativo dos participantes, dissolvendo em algum grau a dicotomia ator e espectador, e, de outro, a instauração em alguma medida de uma condição de liminaridade, ou seja, de "abertura existencial”, que permite a emergência de novos sentidos. É no calor da espiral que a experiência estética ganha força de transformação quando os "compostos de sensação" da cena afetam os 
participantes (atores e espectadores) antes que o pensamento tenha tempo de acionar seus mecanismos de defesa e abstração, e, então, veem-se já engajados, abertos para algo fora de si, em uma condição propícia à reformulação e reinvenção de campos de sentido.

Mas, se a performance cênica começa com o encontro entre atores e espectadores, pressupondo um compartilhamento espacial e temporal, o que acontece com a performance cênica quando forçamos a ideia de distância até limites intransponíveis no espaço ou no tempo, ou seja: o que dizer sobre a formação de uma espiral de retroalimentação autopoiética entre atores e espectadores no contexto da sua reprodução? Podemos começar com o ponto de vista de Peggy Phelan, para quem o caráter de acontecimento da performance cênica não admite a sua reprodução por meios tecnológicos.

A única vida da performance é no presente. Performance não pode ser salva, gravada, documentada, ou de outra forma participar na circulação de representações de representações: quando isso acontece, ela se torna outra coisa que não performance. Na medida em que a performance tenta entrar a economia da reprodução, ela trai e diminui a promessa de sua própria ontologia (Phelan, 1993, p.146 - grifo da autora).

O que Phelan considera como o "ser" da performance está fundado em seu caráter efêmero, de desaparecimento no instante mesmo em que aparece. Daí emana sua força e sua razão de existir. Mas com isso ela estabelece uma dicotomia entre a performance ao vivo e a sua reprodução (ou registro) que é problematizada por Philip Auslander. Ele inicia seu texto A performatividade na documentação de performances (2006), analisando duas imagens icônicas da história da performance e da body art. 
Figura 1 - Shoot (1971) de Chris Burden - registro fotográfico da performance

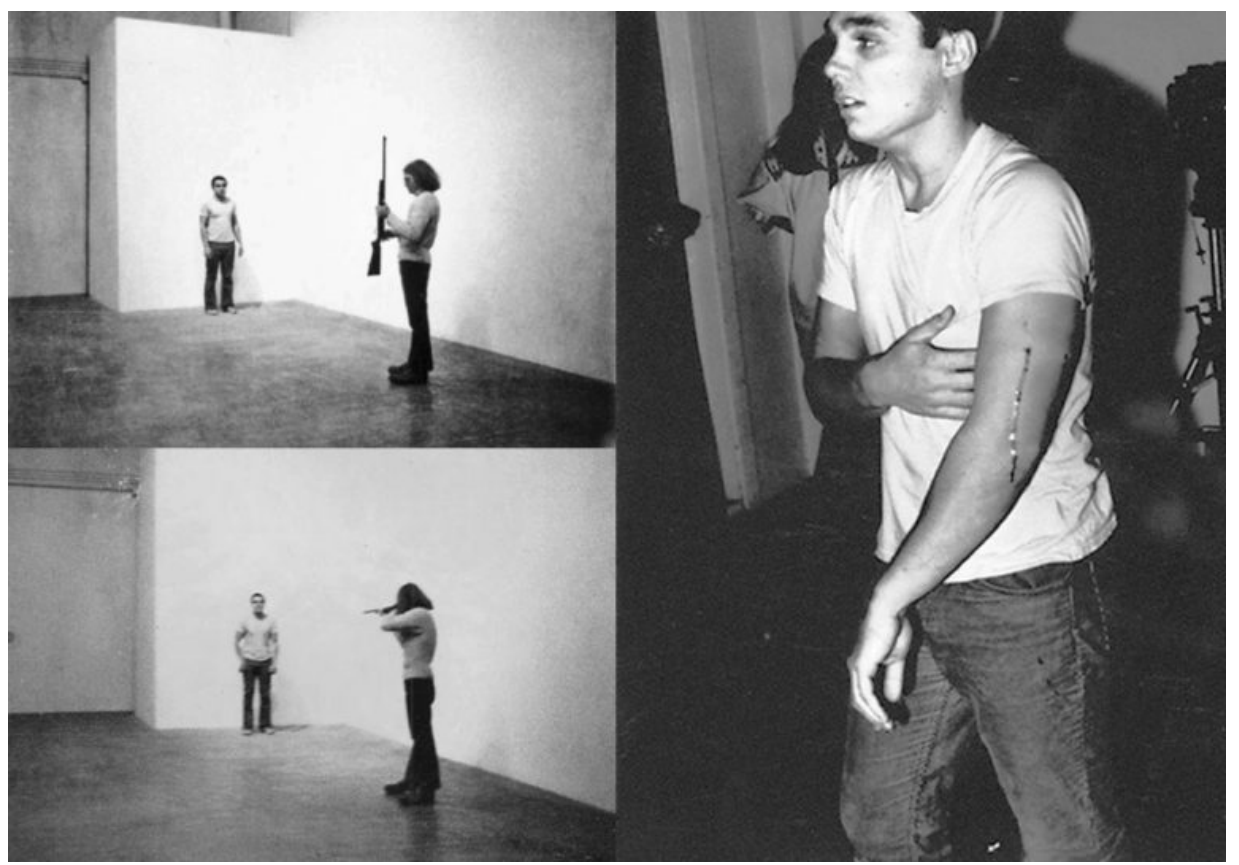

Figura 2 - Leap into the void (1960) de Yves Klein - making of e fotografia final ${ }^{8}$
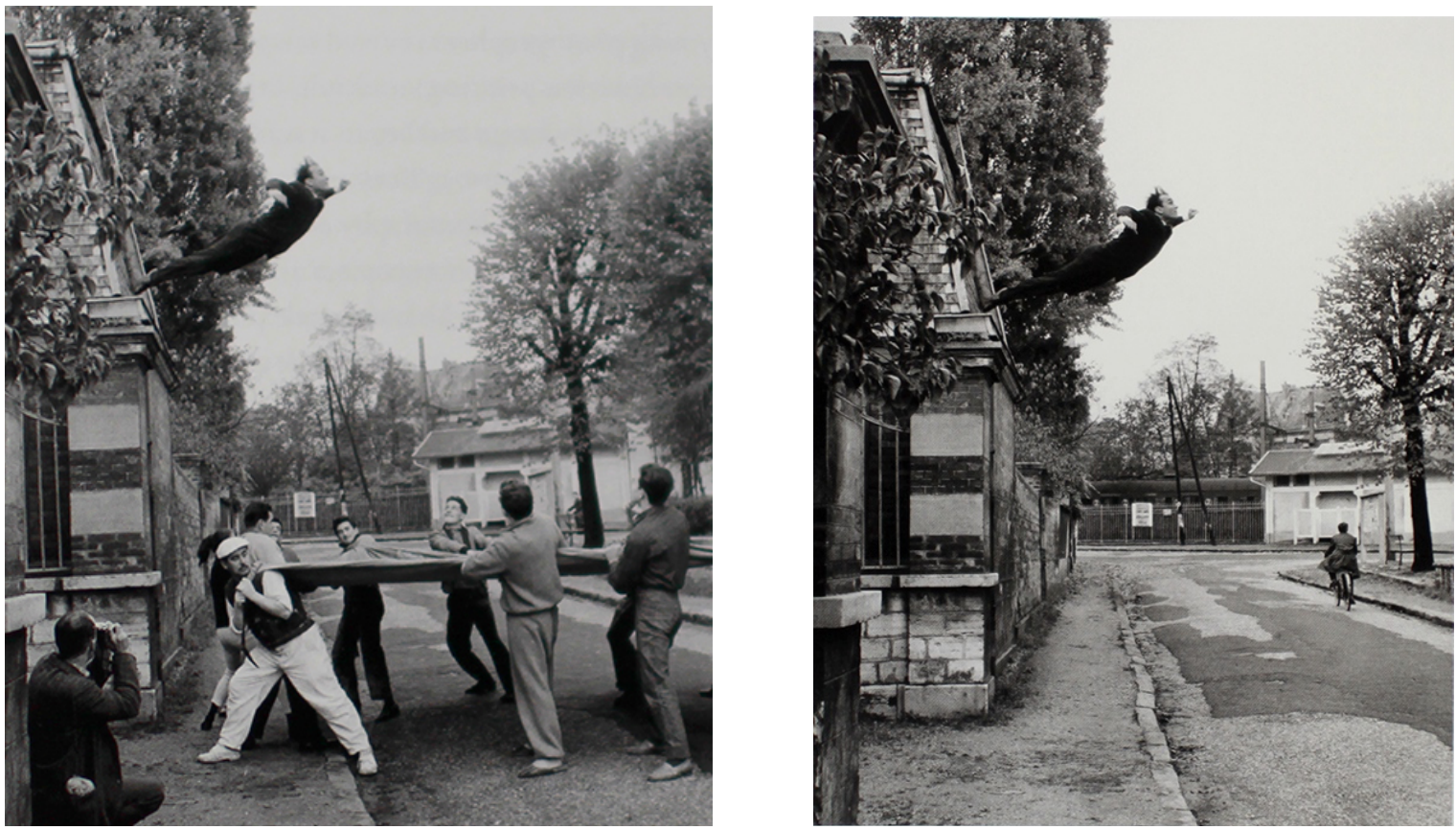

Fonte: <https://arteref.com/arte-no-mundo/conheca-chris-burden-e-o-extremo-do-body-art/> Acesso em: 11 jul. 2019.

${ }^{8}$ Fonte: https://www.dobrasvisuais.com.br/2013/04/a-pequena-historia-de-leap-into-the-void/ Acesso em: 11 jul. 2019 
A primeira é a documentação fotográfica, feita por um amigo, de Chris Burden realmente tomando um tiro no braço em uma galeria de arte. A segunda é a fotografia (montada) de Klein saltando sobre a rua de uma janela no segundo andar. Pergunta de Auslander (2006): se a primeira é por ele definida como um registro documental, uma comprovação de que a performance realmente aconteceu, o que seria a segunda? Ele a categoriza como um registro teatral, na linha das "fotografias performadas" de Marcel Duchamp e Salvador Dalí. Em uma perspectiva tradicional ("ontológica”), as duas categorias de registro são mutuamente excludentes, assim como o seriam a performance ao vivo e o seu registro. Mas ele chama a atenção para o quanto em ambos os casos, como na maioria da produção performática contemporânea, a preocupação com o posicionamento da câmera é uma constante. Trabalhos icônicos, como o de Chris Burden, "não eram performances autônomas cuja documentação suplementa e fornece acesso ao evento original. Os eventos eram encenados para serem documentados tanto quanto para serem vistos por uma audiência” (Auslander, 2019, p.341). Esta constatação é estendida pelo autor às performances populares contemporâneas - musicais, shows de variedades, cultos religiosos - em que a performance para a câmera ganhou tal importância que eventos essencialmente presenciais passaram a emular procedimentos de transmissões televisivas, em um esforço para assegurar a sua "realidade" nos termos de uma sociedade mediatizada.

A dicotomia entre performance e reprodução defendida por Peggy Phelan é ainda relativizada quando Auslander retoma o sentido do conceito de performativo como J. L. Austin o definiu, como um ato de fala. É possível dizer que, ao enunciado performativo "Eu aceito", dito em uma cerimônia de casamento, corresponderia o enunciado constatativo "ela se casou", dito em outro contexto depois do casamento realizado. O enunciado constatativo funciona assim como um registro, uma referência ao acontecimento original, da mesma forma que o registro fotográfico, fonográfico ou audiovisual refere-se à performance ao vivo. Ora, vimos o quanto esta fronteira é problemática, mesmo para Austin: enunciados constatativos funcionam como performativos dependendo da forma e do contexto 
em que eles são enunciados. Para Auslander, algo análogo se passa com a documentação: ela "não simplesmente gera uma imagem/declaração que descreve a autonomia da performance e afirma que ela ocorreu, ela produz um evento como performance" (Auslander, 2019, p. 343). Considerando nossa revisão, devemos acrescentar: dependendo da forma e do contexto em que ocorrem as reproduções, temos aí, também, uma performance potencialmente performativa. Com efeito, a espiral de retroalimentação autopoiética "original" da performance registrada é perdida em sua reprodução, mas quando analisamos a distinção entre os registros documental e teatral inicialmente propostos por Auslander, sua sugestão é que a arte da performance é constituída também pela performatividade de sua documentação. Para deixar mais claro...

Se me permitem uma analogia com outra forma cultural para argumentar que o salto de Klein não era uma performance, porque ele ocorreu somente dentro do espaço da fotografia, equivaleria dizer que os Beatles não executaram a música em seu álbum Sgt. Pepper's Lonely Hearts Club Band porque a performance somente existe no espaço da gravação: o grupo realmente nunca executou a música como a ouvimos. Eu consideraria qualquer alegação desse tipo absurda: é obvio que os Beatles executaram a música - de qual outra maneira há de se entender a execução da música senão como uma performance dos Beatles? Do mesmo modo, está claro que Yves Klein performou seu salto (Auslander, 2019, p.347).

A documentação/reprodução seria assim como uma extensão do ato performativo ou um novo ato performativo em si. Este ponto remete diretamente à problemática da "autenticidade" do acontecimento - e da matéria mesmo - da performance cênica. Mas de que "autêntico" estamos falando? Qual é a "origem" do acontecimento em questão? Como diz Auslander, um critério de autenticidade do registro da performance nos levaria a questionar também a autenticidade das "circunstâncias subjacentes da performance as quais podem ou não estar evidentes na documentação" (Auslander, 2019, p.349). Acrescentamos: podem ou não estar evidentes também na performance ao vivo. De fato, nunca estamos em condições, pela percepção ou pensamento, de acessar origens, essências ou 
verdades, mas apenas efeitos de superfície, acontecimentos ${ }^{9}$. Ou ainda, como conclui Auslander (2019, p. 349):

Talvez a autenticidade do documento de performance resida em sua relação com o seu observador e não como um evento ostensivamente originário: sua autoridade pode ser fenomenológica e não ontológica. [...] Pode ser que o nosso sentido de presença em relação a essas peças derive não do fato de tratarmos o documento como um índice de acesso a um evento que ocorreu no passado, mas de perceber o próprio documento como uma performance que remete diretamente a um projeto estético - ou sensibilidade de um artista - e para o qual somos o publico presente.

Este caráter autônomo, múltiplo, da performance cênica, descolado de uma noção de origem ou modelo, dialoga diretamente, a nosso ver, com o conceito deleuziano de simulacro.

\section{Simulacro e performatividade}

No primeiro anexo de Lógica do Sentido (Platão e o Simulacro), Deleuze opõese a Platão ao afirmar que o simulacro não é, como declarava o filósofo grego, uma cópia degradada: "ele encerra uma potência positiva que nega tanto o original como a cópia, tanto o modelo como a reprodução. [...]. Não basta nem mesmo invocar um modelo do Outro, pois nenhum modelo resiste à vertigem do simulacro" (Deleuze, 2015, p. 267). O caso, aqui, é que afirmar o simulacro não é meramente um gesto opositivo à concepção platônica, o que seria ainda uma forma de submissão - pela negação - à relação de modelo e cópia, mas uma atitude de afirmação radical da imanência da vida como princípio e destino da ação do pensamento.

Em seu texto Intensidade e individuação: Deleuze e os dois sentidos da estética, Cíntia Vieira da Silvia aponta que o valor das imagens simuladas passa a ser estabelecido a partir delas mesmas, ou, ainda, "dos efeitos que elas produzem, e não de qualquer semelhança ou dessemelhança com relação a um modelo”

${ }^{9}$ Como disse Deleuze (1998, p.11), referindo-se ao pensamento de Sartre: "Como todas as coisas e pessoas criadoras, ele está no meio, ele brota pelo meio." 
(Silva, 2017, p. 20). O simulacro suprime a força de modelos, cópias, essências e outros pretensos fundamentos do pensamento. Ao invés disso, teremos a imagem-simulacro de uma singularidade, um acontecimento, e a circunstância de sua sobrevivência (e prosperidade) no pensamento será determinada pela força do encontro, pela sua capacidade de interessar, mobilizar questões, respostas, hipóteses...

Vide a forma como Deleuze se volta para as obras de arte, nas palavras de Anne Sauvagnargues (2013, p.2), "como um terreno para experimentação e validação que nos permite capturar a fabricação conceitual da vida de sua filosofia". Esta desierarquização entre imagens "reais" e simuladas, para Cíntia Vieira da Silvia, faz com que toda a filosofia deleuziana possa ser encarada como uma estética, não no sentido de uma disciplina dentro da filosofia, mas no de uma "teoria da sensibilidade": sendo uma singularidade (tal obra, tal acontecimento, um efeito óptico entre outros), a imagem artística - assim como qualquer outra, do ponto de vista de uma imagem-simulacro - não estará subalternamente a serviço da representação de uma verdade interior a ela (ou anterior: aquilo que habitualmente receberia o nome de "real") ${ }^{10}$. Para a autora, a questão, segundo Deleuze, diz respeito à intensidade da potência dos efeitos que as imagens, sejam elas "artísticas" ou não, são capazes de produzir: "É no acaso de um encontro que a sensibilidade é engendrada e, sob o violento impacto desse encontro, tem inicio a 'gênese do ato de pensar no próprio pensamento'” (Silva, 2017, p.22). Quando Deleuze diz, no prólogo de Diferença e Repetição (2018), que "o mundo moderno é o dos simulacros", não há aí uma crítica a uma suposta desconexão contemporânea em relação à "experiência direta" da imanência da vida. É justamente o contrário. Para ele, a falência geral da representação (da tríade eumundo-deus), que define a modernidade, é uma oportunidade para descobrir que todas as identidades são na verdade simuladas, "efeitos óticos" do jogo mais profundo, o da diferença e da repetição.

${ }^{10}$ Cíntia Vieira da Silvia cita a seguinte passagem do já mencionado anexo da Lógica do Sentido: "A estética sofre de uma dualidade dilacerante. Designa de um lado a teoria da sensibilidade como forma da experiência possível; de outro, a teoria da arte como reflexão da experiência real. Para que os dois sentidos se juntem é preciso que as próprias condições da experiência em geral se tornem condições da experiência real; a obra de arte, de seu lado aparece então realmente como experimentação” (Deleuze, 2015, p. 265-266). 
O simulacro, na medida em que se insinua por toda parte e desmonta hierarquias entre modelos e imagens, sujeitos e objetos, centros e periferias, "real" e "ficcional", evidencia a univocidade da diferença na experiência e no pensamento. O importante é que a apreciação da diferença de intensidades seja considerada, ela mesma, em seu potencial mobilizador e não valorada por uma identidade a priori. Roberto Machado chega a definir o jogo deleuziano como um "teatro filosófico" (2014, p. 5): "Para ele, repetir o texto não é buscar sua identidade, mas afirmar sua diferença. A leitura dos filósofos - e não filósofos - que ele realiza age, atua, interfere com o objetivo de produzir um duplo." Um duplo, um simulacro que, diriam, é o seu "próprio" pensamento, singularidade resultante da ressonância e torção de outros tantos simulacros. E, assim como o pensamento, imagens de performances correm o mundo, participando, de formas infinitas, de novos atos performativos. Aí está a força virtual e, portanto, real de pixels ou fragmentos luminosos na constituição de novas espirais de retroalimentação autopoiética no tempo e espaço em que aparecem.

\section{Referências}

AUSLANDER, Philip. A performatividade na documentação de performances. Tradução: Isabela de Oliveira Barbosa. Revisão: Luciano Vinhosa. In: Revista Poiesis, Rio de Janeiro, v. 20, n. 33, p. 337-352, 2019. Disponível em: <https:// http://periodicos.uff.br/poiesis/article/view/29014> Acesso em: 11 jul. 2019.

AUSTIN, John Landshaw. Quando dizer é fazer. Tradução: Danilo Marcondes de Souza Filho. Porto Alegre: Artes Médicas, 1990.

BUTLER, Judith. Os atos performativos e a constituição do gênero: um ensaio sobre fenomenologia e teoria feminista. Chão da Feira, Caderno n. 78, p. 1-16, 2018. Disponível em: < https://chaodafeira.com/catalogo/caderno78/> Acesso em: 4 abr. 2019.

COLLING, Leandro. O que performances e seus estudos têm a ensinar para a teoria da performatividade de gênero? Urdimento, Florianópolis, v. 1, n. 40, mar./abr. 2021. Disponível em: https://www.revistas.udesc.br/index.php/urdimento/issue/view/789. Acesso em: 30 jan. 2021. 
DELEUZE, Gilles. Diferença e repetição. Tradução: Luiz Orlandi e Roberto Machado. 1. ed. Rio de Janeiro e São Paulo: Paz e Terra, 2018.

DELEUZE, Gilles. Lógica do sentido. Tradução: Luiz Roberto Salinas Fontes. 5. ed. São Paulo: Perspectiva, 2015.

DELEUZE, Gilles. Foucault. Tradução: Claudia Sant'Anna Martins. São Paulo: Editora Brasiliense, 1988.

DELEUZE, Gilles; PARNET, Claire. Diálogos. Tradução: Eloisa Araújo Ribairo. São Paulo: Escuta, 1998.

DELEUZE, Gilles; GUATTARI, Félix. Mil platôs - capitalismo e esquizofrenia. Vol. 2. Tradução: Ana Lúcia de Oliveira e Lúcia Cláudia Leão. Rio de Janeiro: Editora 34, 1995.

FISCHER-LICHTE, Erika. A cultura como performance: desenvolver um conceito. In: Revista Sinais de Cena, Lisboa, n. 4, p. 73-80, 2005. Disponível em: < https://revistas.rcaap.pt/sdc/issue/view/757 > Acesso em: 30 mai. 2019.

FISCHER-LICHTE, Erika. Ästhetik des Performativen. Berlim: Suhrkamp Verlag, 2004

FISCHER-LICHTE, Erika. Estética de lo performativo. Tradução para o espanhol: Diana González Martín e David Martínez Perucha. Madrid: Abada Editores, 2011.

GOFFMAN, Erving. Frame analysis: an essay on the organization of experience. Boston: Northeast University Press, 1986.

MACHADO, Roberto. A Geografia do pensamento filosófico. 2014. Disponível em: <http://deleuze.tausendplateaus.de/wp-content/uploads/2014/10/> Acesso em: 28 out. 2017.

MATURANA, Humberto; VARELA, Francisco. El árbol del conocimiento: las bases biológicas del entendimento humano. Buenos Aires: Lumen, 2003.

MERLEAU-PONTY, Maurice. Fenomenologia da percepção. Tradução: Carlos Alberto Ribeiro de Moura. 2 ed. São Paulo: Martins Fontes, 1999.

PHELAN, Peggy. Unmarked - the politics of performance. Londres e New York: Routledge, 1993.

SAUVAGNARGUES, Anne. Deleuze and Art. Tradução: Samantha Bankston. Bloomsbury Publishing: Londres, 2013.

SILVA, Cíntia Vieira da. Intensidade e individuação: Deleuze e os dois sentidos de estética. Revista de Filosofia Aurora, [S.l.], v. 29, n. 46, p. 17-34, abr. 2017. Disponível em: https://periodicos.pucpr.br/index.php/aurora/article/view/5624. Acesso em: 30 out. 2019. 
ZOURABICHVILI, François. Deleuze: uma filosofia do acontecimento. Tradução: Luiz B. L. Orlandi. São Paulo: Editora 34, 2016.

Recebido em: 13/03/2021

Aprovado em: 04/06/2021 